Development of a Civil Engineering Capstone Design Course for a New Program

Dr. David A Saftner, University of Minnesota Duluth

Ms. Sara D. Ojard, University of Minnesota Duluth

Dr. Eshan V. Dave, University of Minnesota, Duluth

Dr. Nathan William Johnson, University of Minnesota Duluth

Prof. Eil Kwon

Dr. Rebecca Teasley, Civil Engineering University of Minnesota Duluth 


\title{
Development of a Civil Engineering Capstone Design Course for a New Program
}

\begin{abstract}
The University of Minnesota Duluth's Department of Civil Engineering accepted its first students in 2008, graduated its first class in 2012, and first offered a capstone design course in the spring semester, 2012. Groups of five to six students designed a building on a local site. Students organized their teams based on interest in a particular branch of civil engineering, allowing individual students to focus their efforts on a particular subject. Based on feedback from faculty, practicing engineers, and students, several changes were implemented prior to the fall 2012 semester. These changes included making the group size smaller, modifying the graded submissions, and changing the project location. Most significantly, the course was reorganized to prevent students from working the entire semester in one area of civil engineering while doing little to no work in other areas. This paper compares the different capstone design experiences. Results from the analysis are part of a larger comparison between narrow, in-depth and broad, general approaches to design experiences for undergraduate civil engineering students.
\end{abstract}

\section{INTRODUCTION}

The objective of this paper is to compare two methods of conducting a capstone design course at a new civil engineering program. The capstone design experience has become a standard part of engineering education. Both preparation for entering the engineering work force and an ABET emphasis on a major design experience were motivation for the trend to require capstone design courses [1]. However, there is not a single accepted method of conducting the course. Based on faculty experience with capstone design courses at other universities and advice from the department's Industrial Advisory Board (IAB), the senior design course was based on the design of a building on a site close to the University of Minnesota Duluth (UMD). In the first semester the capstone design course was offered, students formed subgroups within their assigned teams with individuals focused in a particular area of civil engineering. During the second semester the course was offered, the students worked in all areas, focusing on each for a portion of the semester. This paper compares a narrow, in-depth capstone design experience to a broad, general experience.

First, the framework for the UMD's capstone design course is described. In the next section, each of the projects is described in more detail. While several changes were made to the course before its second offering, the major change was requiring a broader experience spanning several areas of civil engineering. Finally, the summary of interviews with students, the IAB, and the practicing engineers who acted as advisors on the projects are presented.

\section{CAPSTONE DESIGN PROJECT SUMMARY}

When developing the form of the capstone design project, two models were considered. The first was assigning each student group a different project focused in their interest area under the supervision of an individual faculty member. These projects could be industry sponsored, encouraging interaction between students and practicing engineers and adding a "real world" component to the project. The second model was assigning student groups a multi-disciplinary 
project under the direction of a single faculty member, with other faculty members serving as consultants on the project. After consultation with the IAB, the second model was chosen because of resources available at the time and faculty experience with similar models from previous universities.

During the 2012 spring semester, the project required students to design an educational facility on a small, local site. The site was in a commercial area with nearby access to highways. Additionally, several creeks on the site fed into larger bodies of water in the area. Soil borings were created based on local experience in the area reflecting the known conditions at the site. Three group project submittals were required, each including an environmental, geotechnical, hydrological, structural, and transportation component. These oral presentations and written reports represented $20 \%, 50 \%$, and $100 \%$ design submittals. Five to six students were assigned to each group using a random number generator. Following the random assignment, the only changes to the groups involved ensuring that each group contained a student with an expressed interest in each of focus areas within civil engineering. Local engineers with expertise in each area of civil engineering were invited to participate in the course. They were initially involved in determining the project parameters and defining each submittal's requirements. During the semester, they acted as mentors to the students in the class, coming to class on a regular basis to answer questions and provide advice. Additionally, the practicing engineers attended student presentations for each submittal, providing feedback on the technical content and communication style.

After collecting and synthesizing student, professional engineer, and faculty feedback, several changes were implemented for the 2012 fall semester when a new group of students registered for the course. These changes focused on the impact of students' in-depth experience in one area of civil engineering (i.e. environmental, geotechnical, hydrological, structural, or transportation), while doing little work in other components. In the updated course model, the design project was modified to a site with broader implications for affecting existing civil infrastructure. The structure was changed from an educational facility to a shopping center, increasing the building's footprint and traffic demand. The site was moved to a rural area along an interstate close to a state park and wetlands. Additionally, student group size was reduced to four and major changes were implemented to the content of the submittals. The first submission focused on choosing a specific site within a larger available area, accounting for, among other factors, environmental, hydrological, traffic, and construction concerns. Subsequent submissions focused on geotechnical, then structural and site civil features. Local engineers were still involved in each phase of the projects and provided mentorship in much the same way as the previous semester when students were focused on their area of expertise. Changing the submitals to focus on certain aspects of the project was intended to prevent the smaller student groups from organizing themselves into subgroups which dealt only with a narrow portion of the project. Thus, the intent of the updated course was to provide a broader, but more general experience for each student.

\section{METHODS}

A descriptive qualitative study utilizing semi-structured interviews to compare the two methods of conducting a capstone design course was conducted [2]. The interview data used in this study came from three sources: senior exit interviews, IAB meeting notes, and interviews with the practicing engineers who mentored students in both semesters. 
Exit interviews are conducted with every student graduating from the department. These interviews are used to improve the undergraduate education and experience offered by the department and gather assessment data. The interview questions were prepared by a small group of faculty and were approved by the department as a whole. While there were several questions focused on a variety of issues, one question concerned the capstone design course. Following the first semester, the question was general and asked student's opinion of the senior design experience. Following the second semester, the same general question was asked in addition to asking student's opinion of their broad experience in comparison to the earlier in-depth experience. In each semester, various faculty members conducted exit interviews with groups of three or four students. All faculty members took notes on their interviews with the intent of disseminating the information among the faculty.

The department faculty meets twice a year with the IAB. The IAB consists of senior engineers representing public and private interest in the local area. While no IAB member worked directly with the students in the capstone design course, many of the members on the IAB represented companies and agencies which had provided mentors to the capstone design course. In November, 2012, one agenda item on the IAB meeting was the capstone design course. Those present were asked their opinion of the structure of the course. Data from the IAB came from notes taken during the meeting.

Finally, three practicing engineers served as mentors during both semesters. A set of interview questions was developed by the faculty involved in the course. One faculty member conducted phone interviews with each of the practicing engineers using the same set of questions. Ten other practicing engineers were involved in one of the two semesters. Interviews with these engineers are not yet available.

These semi-structured interviews are part of the department's efforts to improve and were not originally intended for a research study comparing the two methods of conducting a capstone design course. While faculty did ensure consistent questions and note taking when more than one interviewer was involved, as was the case with the senior exit interviews, the interviews were not recorded and transcripts are not available. After completion of the interviews, it was determined that this information may be helpful to other programs developing or changing their capstone design course. At that point, the data was analyzed using Glaser's constant comparative method [3].

The constant comparative method consists of three levels of coding. First, a line-by-line analysis of notes from the senior exit interviews, the IAB meeting, and interviews with practicing engineers identified themes in the data. Second, these themes were assigned to categories containing similar information. After ensuring that the categories were mutually exclusive, the number of categories was reduced by comparing them to each other and identifying higher order categories explaining the results [3].

\section{RESULTS \& DISCUSSION}

The results of data analysis produced three main themes. These themes include: advantages and disadvantages of each method, preparation for real world engineering, and level of student interest in a specialty area of civil engineering. 
The participants mentioned several advantages and disadvantages to both capstone design methods. Disadvantages of the model where the students' role was specialized included minimal communication between team members, students not working in the specialty in which they had the greatest interest, and the sequencing of the project. A practicing engineer stated that the communication in this model was only enough to convey information that another specialty required. A student exit interview group said that some specialties did not interact with other specialties. Student exit interview also revealed that not every student was able to work in the specialty area of their choice, limiting their interest in the project. Practicing engineers argued that each specialty does not move through the design at the same time. This led to unrealistic sequencing in the specialized model, where students work in each specialty presented $20 \%, 50 \%$, and $100 \%$ design simultaneously. Advantages of broad capstone design method are the reverse of what is discussed here.

Disadvantages of the broader course included minimal opportunity to review completed work and improve it based on feedback, a lack of advanced learning in student's interest area, some groups continue to segregate themselves into specialties, and students putting forth minimal effort were less likely to be identified. Practicing engineers stated that the broad course moved fairly quickly from one submittal focused on a specialty area to the next. Students did not have the opportunity to revisit previous areas and improve their designs. Additionally, practicing engineers noted that students with a strong interest in one specialty area did not have an opportunity for advanced learning in that area. Students brought up that some groups in the broad course still segregated themselves into specialty areas, with individual students doing the majority of the work for some submittals and little or simple supporting work in other submittals. Finally, student exit interviews identified that the structure of the project allowed students putting minimal effort into the project to "hide" in this model. The improvement of these issues in the specialized course represent its advantages.

Despite the advantages and disadvantages of each capstone design experience, the students, IAB, and practicing engineers were convinced that both methods were valuable preparation for the jobs the students could expect to begin following graduation. Students mentioned several points supporting this theme during their exit interviews. Both capstone design experiences raised their confidence in their preparation for employment by exposing them to challenges that they did not initially know how to solve and giving them the opportunity to successfully work through them. The real world perspective and examples from the mentors were also mentioned. Students felt that this class demonstrated that they do not graduate with a comprehensive set of technical skills, but with the ability to solve problems and learn what is necessary to solve the problems they will face.

The IAB and practicing engineers provided similar feedback on the theme of preparing students for employment. The IAB stated that both breadth and depth of knowledge are important for the people they want to hire and believe the department's current curriculum ensures graduates preparation. They believed that the broad capstone design experience mimics realistic experience in smaller public and private entities, while the specialized model compares closer to what occurs at larger consulting firms and government agencies. Practicing engineers maintained that students learned in each model. One mentor stated the broad capstone model was similar to the engineer's experience in a small, diverse firm, while the specialized experience reflected the engineer's current experience of practice groups interacting in a large consulting firm. 
The final theme was level of student interest in a specialty interest. One student group in the broad course mentioned that a particular submission was difficult due to a lack of expertise and motivation because no one in their group had significant interest in the area that was the focus of the submission. Similarly, practicing engineers thought that students with strong interest in a particular area of civil engineering had more opportunities and a better experience in the specialized model. However, students from the broader course mentioned in exit interviews that the opportunity to work in all areas of civil engineering helped clarify their desired career path. The practicing engineers reinforced this, observing that students without a clear interest area did not become frustrated working in a single area and were able to discuss career options with a greater variety of mentors.

In summary, the results show that both course models met the goal of preparing students for employment as civil engineers. Many of the advantages and disadvantages could be addressed by adapting the current course models. For example, in the specialized model, the project could be set up in a manner that required more communication between specialty areas. Likewise, the submission requirements could be changed in the broad model to allow students to change and improve their designs based on feedback. However, some issues, such as students working outside their specialty interest in the specialized model and less opportunity for advanced learning in the broad model, are less likely to be fixed through minor course modifications. The distinction between the models becomes important when comparing individual student's interest and career goals. Students with a clear interest in a particular area within civil engineering or a clear goal of working for a large firm or agency would benefit from a capstone design experience that emphasizes specialization. A broader capstone design course is better for students without a preference for a specialty area or with a desire to work in a smaller, diverse engineering group.

\section{CONCLUSION}

Using data from semi-structured interviews with students, the department's IAB, and practicing engineers involved in mentoring students during a capstone design experience, two methods of conducting a capstone design course at a new civil engineering program were examined. In the first course, students worked on a multi-disciplinary team on a particular specialty within civil engineering. The second time the course was taught, smaller student groups worked on a project while focusing on a particular specialty area at a time. The paper compared an in-depth, narrow method of conducting a capstone design course to the broad, general method.

Using the constant comparative method, three themes in the data were identified: advantages and disadvantages of specialized and broad capstone design courses, preparation for real world engineering, and level of student interest in a specialty area of civil engineering. Advantages and disadvantages with each model were identified. While some of the disadvantages could be addressed through relatively minor course changes, some were a function of the specialized or broad approach. Both methods of capstone design are a valuable part of preparing civil engineers for practice. The broad model suits students without an interest in a specialty area or with an interest in working in a smaller setting. The specialized model benefits students with a strong preference for a particular specialization within civil engineering or a plan to work for larger firms or agencies where specialization is standard. 


\section{ACKNOWLEDGEMENTS}

Mr. Pat Leow, Ms. Sara Leow, and Mr. Victor Lund mentored students in both semesters and provided valuable feedback comparing the different models of capstone design. Their participation in both semesters greatly improved the quality of the course. Dr. Melissa Saftner's guidance on the constant comparative method was instrumental to this work. This support and assistance is gratefully acknowledged.

\section{BIBLIOGRAPHY}

[1] ABET Engineering Accreditation Commission, 2013. Criteria for Accrediting Engineering Programs: Effective for Reviews During the 2013-2014 Accreditation Cycle, October 2012, <>, accessed on January 2, 2013.

[2] Sandelowski, Margarete, 2000. "Whatever Happened to Qualitative Description?," Research in Nursing \& Health, 23, 334-340.

[3] Glaser, B., 1978. Theoretical Sensitivity. Mill Valley, CA: The Sociology Press. 